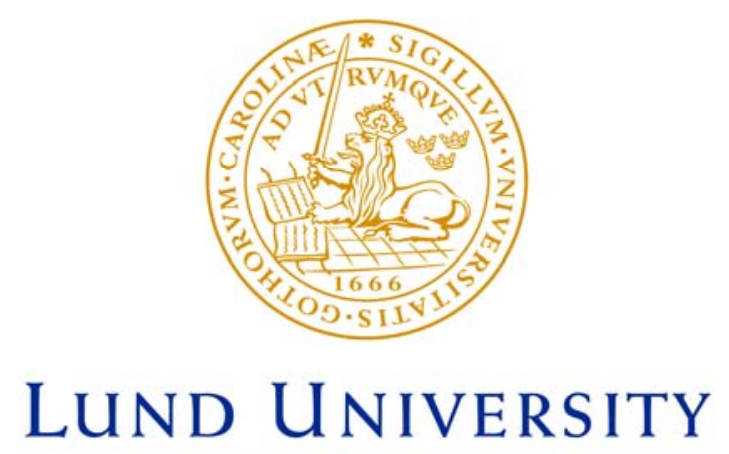

Faculty of Medicine

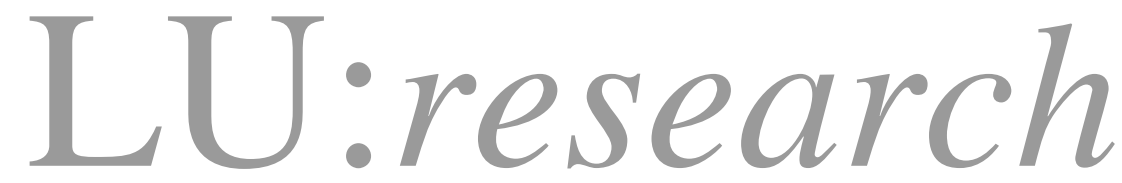

Institutional Repository of Lund University

This is an author produced version of a paper published in

Graefe's archive for clinical and experimental ophthalmology. This paper has been peer-reviewed but does not include the final publisher proof-corrections or journal pagination.

Citation for the published paper:

Wallentén, Karin and Malmsjo, Malin

and Andréasson, Sten and Wackenfors, Angelica and Johansson, Kristina and Ghosh, Fredrik.

"Retinal function and PKC alpha expression after focal laser photocoagulation."

Graefes Arch Clin Exp Ophthalmol, 2007, Vol: Jul 17; [Epub ahead of print]

http://dx.doi.org/10.1007/s00417-007-0646-x

Access to the published version may require journal subscription.

Published with permission from: Springer 


\title{
RETINAL FUNCTION AND PKC ALPHA EXPRESSION AFTER FOCAL LASER PHOTOCOAGULATION
}

\author{
Karin Gjörloff Wallentén ${ }^{1}$, Malin Malmsjö², Sten Andréasson ${ }^{1}$ Angelica Wackenfors ${ }^{2}$, \\ Kristina Johansson ${ }^{1}$ and Fredrik Ghosh ${ }^{1}$ \\ ${ }^{1}$ Department of Ophthalmology, Lund University Hospital, Lund, Sweden, \\ ${ }^{2}$ Department of Medicine, Lund University Hospital, Lund, Sweden
}

\author{
Corresponding author: \\ Dr Fredrik Ghosh \\ Dept. of Ophthalmology \\ University Hospital \\ SE-221 85 Lund \\ Sweden \\ E-mail: fredrik.ghosh@med.lu.se \\ Fax: +46462220774 \\ Phone: +46 462220765
}

Supported by the Faculty of Medicine, Lund University, Crown Princess Margareta's Foundation for the Visually Impaired, the Swedish Research Council, Maggie Stephens Foundation, Synfrämjandets forskningsfond, the Åke Wiberg Foundation, the M. Bergvall Foundation, Anna Lisa and Sven-Eric Lundgrens Foundation for Medical Research, the Anders Otto Swärds Foundation, Ulrika Eklunds Foundation, and the Swedish Medical Association. The authors have no financial relationship with the sponsoring organizations.

The authors have full control of all primary data and agree to allow Graefe's Archive for Clinical and Experimental Ophthalmology to review the data if requested. 


\begin{abstract}
Purpose: To examine the effects of focal laser photocoagulation on general and local retinal function and to relate electrophysiological findings with changes in protein kinase $\mathrm{C}(\mathrm{PKC})$ alpha expression.
\end{abstract}

Methods: Twelve rabbits were treated with 70 spots of laser photocoagulation in the central conerich retina. Operated eyes were investigated with electroretinography (full-field ERG and mfERG) preoperatively and at 1, 3 and 5 weeks after surgery. The expression of $\mathrm{PKC}$ alpha was examined at all 3 time points using immunohistochemistry, and PKC alpha mRNA levels were quantified using real-time PCR. Immunohistochemistry for glial fibrillary acidic protein (GFAP) and hematoxylin and eosin staining was employed to monitor the extent and dynamics of the morphological response.

Results: The full-field ERG revealed a significant increase in b-wave amplitudes derived from the isolated rod response (blue light) at all 3 time points after surgery $(\mathrm{p}<0.05)$. Supernormal $b$-wave amplitudes were also found for the combined rod-cone response at 3 weeks (white light), and for the isolated cone response (light-adapted $30 \mathrm{~Hz}$ flicker) at 5 weeks after treatment. In the mfERG, amplitudes derived from the central retina did not change postoperatively while the implicit time was significantly increased at all time points. Immunohistochemistry for PKC alpha revealed a reduced expression of the enzyme in rod bipolar cells 1 and 3 weeks after laser treatment compared with untreated controls. Five weeks postoperatively, no PKC alpha labeling in rod bipolar cells was found in any part of the retina. Real-time PCR 1 and 3 weeks after treatment displayed a decreased level of PKC alpha mRNA compared to controls. Immunolabeled tissue sections from laser treated eyes displayed GFAP expression in Müller cells in the treated as well as untreated retina 1 week postoperatively. At 3 and 5 weeks, GFAP labeling was less pronounced and was concentrated to the laser treated spots. 
Conclusions: Focal laser treatment in the rabbit eye induces local and wide-spread alterations in both rod and cone mediated retinal function in the form of supernormal b-wave amplitudes in the full-field ERG and increased latency in the mfERG. The electrophysiological abnormalities are accompanied by a progressive down-regulation of the PKC alpha isoenzyme in rod bipolar cells reaching far beyond the treated area. PKC alpha is down-regulated directly by impaired protein synthesis, but possibly also indirectly by protein consumption related to GFAP up-regulation. The results indicate that focal laser photocoagulation interferes with PKC alpha mediated inhibitory regulation of inner retinal signal transmission. 


\section{KEYWORDS}

Full-field electroretinography; Multifocal electroretinography; Glial fibrillary acidic protein 


\section{INTRODUCTION}

Retinal laser photocoagulation is a well established treatment for a variety of retinal and choroidal disorders. After application to the fundus, the inherent energy of the laser light is converted to heat in the retinal pigment epithelium (RPE), causing thermal damage primarily to the RPE and photoreceptors, with secondary effects in the neuroretina and choroid [24]. In the peripheral retina, the scar-healing effect of laser burns is utilized for creating local chorioretinal adhesion around retinal ruptures and for ablation of photoreceptors to reduce ischemia in vaso-proliferative disorders [42]. Focal laser photocoagulation to the macular region is used in cases of age-related macular degeneration associated with choroidal neovascularization and edema caused by diabetic retinopathy or branch vein occlusion $[5,37,38]$. Some of the complications of laser photocoagulation, such as decreased peripheral, color and night vision after pan-retinal treatment and loss of macular function after focal treatment, can be related to the destruction of photoreceptors $[4,13,15,21,32]$. Other complications remain enigmatic, such as loss of function in untreated areas, development of macula pucker after treatment of peripheral retinal ruptures, and induction of proliferative vitreoretinopathy after limited peripheral treatment $[4,13,19,34]$. Experimental studies on retinal function and morphology after laser photocoagulation often involve protocols of pan-retinal treatment, resulting in the destruction of large parts of the outer retina and a substantially decreased function $[3,14,22,35]$. Focal laser photocoagulation has been used in a few, well designed, laboratory investigations, which have provided insight into more subtle postoperative changes in the retinal morphology $[17,33]$. However, no detailed analysis of retinal function after focal laser photocoagulation in the experimental situation has been performed. We have previously reported that focal laser photocoagulation in the rabbit eye induces a profound down-regulation of protein kinase $\mathrm{C}(\mathrm{PKC})$ alpha, one of the key regulators of phototransduction and inner retinal signal transmission $[9,43]$. With the present study, we wanted to examine whether focal treatment also alters the general and local retinal 
function and if such alterations could be related to down-regulation of PKC alpha. We also wanted to explore cellular mechanisms behind any change in $\mathrm{PKC}$ alpha expression, and if possible relate such change to GFAP expression. To this end, we have used standardized protocols for full-field ERG and mfERG before and after treatment, combined with PKC alpha and GFAP immunohistochemistry as well as PKC alpha real-time PCR [10,11]. 


\section{MATERIALS AND METHODS}

\section{Laser photocoagulation}

A total of 12 pigmented rabbits of mixed strain, aged 4-5 months, were used for surgery. The right eye was instilled with cyclopentolate (1\%) and phenylephrine (10\%) $30 \mathrm{~min}$. prior to surgery. The animals were sedated with an intramuscular injection of $1.5 \mathrm{ml}$ of Hypnorm ${ }^{\circledR}$ (fentanylcitrate $0.315 \mathrm{mg} / \mathrm{ml}$ and fluanisone $10 \mathrm{mg} / \mathrm{ml}$ Janssen Pharmaceutica Beerse, Belgium). Topical tetracaine $(0.5 \%)$ was applied just before surgery. Seventy laser burns were applied to the fundus, using an indirect ophthalmoscope delivery system and a 25 diopter condensing lens (Fig. 1). The laser spots were placed in an area extending inferiorly from the optic nerve head with a distance of approximately one spot diameter. An EyeLite ${ }^{\circledR} 532 \mathrm{~nm}$ frequency-doubled YAG laser photocoagulator (Alcon Laboratories Inc., Forth Worth, USA) was used, creating grayish/white burns ( $0.2 \mathrm{sec}$ and 0.12-0.2W). To terminate anaesthesia, Naloxonhydrochloride $0.5 \mathrm{ml}(0.02 \mathrm{mg} / \mathrm{ml}$., Apoteksbolaget, Umeå, Sweden) was delivered intramuscularly. No postoperative treatment was given.

\section{Electrophysiology}

The operated eyes were examined 1 week preoperatively with mfERG (multifocal electroretinography) and full-field ERG. Postoperative examinations were made after 1, 3 and 5 weeks. The protocols for ERG and mfERG examination in the rabbit eye have been previously described, and will only be summarized here $[10,11]$.

\section{Full-field ERG}

The right pupil of each animal was dilated with Cyclogyl ${ }^{\circledR}$ (cyclopentholate hydrochloride 1\%) to a diameter of 8-9 mm. The rabbits were dark-adapted for 40 min and sedated with Hypnorm ${ }^{\circledR}$ (fentanylcitrate $0,315 \mathrm{mg} / \mathrm{ml}$ and fluanisone $10 \mathrm{mg} / \mathrm{ml}$ Janssen Pharmaceutica Beerse, Belgium) 0.2 $\mathrm{ml} / \mathrm{kg}$ intramuscularly. After installation of Oxibuprokain ${ }^{\circledR}$ (oxibuprocaine hydrochloride $0.4 \%$ ), a 
Burian-Allen bipolar contact lens electrode (Hansen Ophthalmic Development Laboratory, Iowa City, Iowa), lubricated with Methocel ${ }^{\circledR}$ (hydroxypropyl-methylcellulose $2 \%$ ), was applied to the cornea. A ground electrode was inserted in the skin behind the ears. Full-field electroretinograms were recorded using the Nicolet Viking analysis system (Nicolet Biomedical Instruments, Madison, WI) following the ISCEV standards for ERG (5). Responses were obtained with a wide-band filter $(-3 \mathrm{~dB}$ at $1 \mathrm{~Hz}$ and $500 \mathrm{~Hz})$. Dark-adapted rod responses were obtained with single full-field flashes (20 $\mu$ s) of dim blue light (Wratten filters \# 47, 47A and 47B), and combined rod and cone responses with white light $(0.8 \mathrm{~cd} . \mathrm{s} / \mathrm{m} 2)$. Light-adapted cone responses were obtained with $30 \mathrm{~Hz}$ flickering white light averaged from 20 sweeps with a background light of 10fL. At each stimulated intensity, the recording was repeated to ensure reproducibility. No extra filter was used.

\section{Multifocal ERG}

The animals were kept in normal room light (120 lux) prior to the stimulation, and the right pupils were dilated with Cyclogyl ${ }^{\circledR}$. General anaesthesia was administered using a combination of ketamine $(35 \mathrm{mg} / \mathrm{kg})$ and xylazine $(5 \mathrm{mg} / \mathrm{kg})$ intramuscularly. Topical tetracaine $(0.5 \%)$ was applied just before surgery. A Burian-Allen contact lens electroretinogram electrode with built-in infrared emitters (Hansen Ophthalmic Development Laboratory, Iowa City, Iowa) lubricated with Methocel® was applied to the eye, and a ground electrode needle was inserted into the skin. The recordings were made using the VERIS Science 4.3 system (Visual evoked Response Imaging System, EDI. San Mateo, CA) developed by Sutter et al. The stimulus consisted of 103 unscaled hexagons and using the infrared camera, the stimulus could be positioned with the optic nerve head at the upper central part of the recording area. In every m-sequence 2 additional blank frames were inserted. The signal gain was 100000 and the filter range 3-300 Hz. No additional notch filtering was added. The luminance flickered between light and dark according to a pseudo-random binary m-sequence of $75 \mathrm{~Hz}$ with a mean stimulus luminance of $16.6 \mathrm{~cd} / \mathrm{m} 2$ and a flash intensity of $1.33 \mathrm{~cd} . \mathrm{sec} / \mathrm{m} 2$. 
Spatial averaging was set to $17 \%$. After each recording a fundus photograph obtained by the infrared camera system was taken to document the positioning of the eye, and a binocular ophthalmoscopic examination was performed.

\section{Statistical analysis of ERG and $m f E R G$ results}

For full field ERG, the b-wave amplitudes for blue light, white light and for $30 \mathrm{~Hz}$ flickering light as well as the implicit times, were compared before and after surgery. For mfERG, amplitudes measured from the most negative (N1) to the most positive point (P1) in the first order kernel were evaluated. Traces derived from the 5 lowest rows of hexagons (corresponding to and somewhat inferior to the visual streak) were grouped and the average amplitude and latency was calculated.

For all parameters, values obtained from the preoperative examination was compared with values obtained from the same animals at 1, 3 and 5 weeks postoperatively using the two-tailed Student's paired t-test. GraphPad InStat, GraphPad Software, San Diego California USA, was used for all calculations. Statistical significance was defined as $\mathrm{p}<0.05$ using the above mentioned test.

\section{Tissue preparation:}

\section{Immunohistochemistry}

At 1, 3 and 5 weeks after surgery, 4 animals at each time point were randomly selected and sacrificed using an intravenous overdose of sodium pentobarbital. Both eyes were enucleated and the anterior segment removed. The eyecups were divided in 2 halves. One half from each eye (operated and unoperated) was used for real time PCR (see below) and the remaining tissue was prepared for histology by fixation in $4 \%$ paraformaldehyde for 4 hours. Specimens were then dissected as approximately $5 \mathrm{~mm}$ wide pieces, including the laser treated area together with the myelinated streak, optic nerve, the visual streak, and the superior and inferior retinal periphery. Serial sectioning at $12 \mu \mathrm{m}$ on a cryostat was subsequently performed. For immunohistochemistry, sections were washed 
in $0.1 \mathrm{M}$ sodium phosphate-buffered saline pH 7.2 (PBS) with $0.25 \%$ Triton X-100 (PBS/Triton) and incubated with the primary antibody overnight at $+4^{\circ} \mathrm{C}$. A monoclonal antibody directed against human PKC (clone MC5; Nordic BioSite, Täby, Sweden) was used, diluted to 1:200 with PBS/ Triton with $1 \%$ bovine serum albumin (BSA). This antibody has been proved specific for PKC alpha in the rabbit retina [43]. Sections were also labeled with an antibody against glial fibrillary acidic protein (GFAP, clone G-A-5; Boehringer Mannheim Scandinavia, Bromma, Sweden) in a dilution of 1:4. After incubation, the slides were rinsed in PBS/Triton, incubated with fluorescein isothiocyanate (FITC)-conjugated antibodies for $45 \mathrm{~min}$, rinsed and mounted in custom-made antifading mounting media.

For negative controls, the same labeling procedure without the primary antibody was performed on both the normal left and the operated right eye of the animals. Specimens were also stained with hematoxylin and eosin. Photographs were obtained with a digital camera system (Olympus, Tokyo, Japan). When comparing immunolabeled sections, specimens were always derived from the same labeling batch, and were photographed in one session using a fixed exposure time and aperture. No digital image manipulation was performed on photographs from immunolabeled sections. Photographs of hematoxylin and eosin stained sectioned were adjusted for brightness.

\section{Real-time polymerase chain reaction (real-time PCR)}

Real-time PCR for PKC alpha was performed at 1 and 3 weeks after surgery. The neuroretinas derived from treated and untreated eyecup halves were dissected free from adhering tissue, frozen in liquid nitrogen, and stored in a $-80^{\circ} \mathrm{C}$ freezer. TRIzol ${ }^{\circledR L S}$ was used for the RNA extraction according to the manufactures instructions (Life Technologies, Paisley, UK). Reverse transcriptase of total RNA to cDNA was carried out using the GeneAmp RNA PCR kit (Perkin-Elmer, Applied Biosystems, Foster City, CA, USA) in a Perkin-Elmer DNA Thermal cycler. First-strand cDNA was synthesized from 0.5 to $1 \mu \mathrm{g}$ total RNA in a $20 \mu \mathrm{l}$ reaction volume using random hexamers as prim- 
ers. Real-time PCR was performed in a GeneAmp 5700 Sequence Detection System (Perkin-Elmer, Applied Biosystems, Foster City, CA, USA) using the GeneAmp SYBR ${ }^{\circledR}$ Green kit (Perkin-Elmer, Applied Biosystems, Foster City, CA, USA) with the cDNA synthesized above as template in a 25 $\mu 1$ reaction volume. The GeneAmp 5700 Sequence Detection System monitors the growth of DNA in real-time using an optic imaging system, via the binding of a fluorescent dye to double-stranded DNA. Specific primers for PKC alpha, and the house-keeping genes beta-actin, elongation factor 1 (EF-1) alpha, and glyceraldehyde 3-phosphate dehydrogenase (GAPDH) were designed as follows:

$\begin{array}{lll}\text { PKC alpha } & \text { forward } & 5^{\prime} \text { - AGGCGACCAGCTATCCAGG-3' } \\ & \text { reverse } & 5^{\prime} \text { - GCGACTCCCACATGATCAAAC-3' } \\ \text { Beta-actin } & \text { forward } & 5^{\prime} \text { - CCTCACCGACTACCTGATGAAGA }-3^{\prime} \\ & \text { reverse } & 5^{\prime} \text { - ACGAAGGAGTAGCCACGCTC }-3^{\prime} \\ \text { EF-1 } & \text { forward } & 5^{\prime}-\text { TATGCCGTGGTTCAAGGGAT }-3^{\prime} \\ & \text { reverse } & 5^{\prime}-\text { CTGGCATTGCCATCTTTGC }-3^{\prime} \\ \text { GAPDH } & \text { forward } & 5^{\prime} \text { - ACTGCTTAGCCCCCCTGG }-3^{\prime} \\ & \text { reverse } & 5^{\prime}-\text { CCACAATGCCGAAGTGGTC }-3^{\prime}\end{array}$

The genes for beta-actin, EF-1 and GAPDH were used as references, since they are continuously expressed in cells.

All proceedings and animal treatment were in accordance with the guidelines and requirements of the Government Committee on Animal Experimentation at Lund University and the "Principles of laboratory animal care" (NIH publication No. 85-23, revised 1985), the OPRR Public Health Service Policy on the Humane Care and Use of Laboratory Animals (revised 1986) and the U.S. Animal Welfare Act, as amended, were followed. 


\section{RESULTS}

\section{Electrophysiology}

Full-field ERG responses from all eyes were well detectable and reproducible. At all 3 time points after surgery, b-wave amplitudes derived from the isolated rod response (blue light) were significantly increased to supernormal levels compared with preoperative values (Fig. 2, Table 1). Amplitudes derived from the combined rod and cone response (white light) were significantly elevated 3 weeks postoperatively, and 5 weeks after treatment the isolated cone response $(30 \mathrm{~Hz}$ flicker) also displayed supernormality. No statistical change in ERG implicit time was seen after treatment (data not shown).

No significant change was found in the mfERG amplitude postoperatively, but the mfERG latency was significantly increased at all 3 time points after surgery (Table 2).

\begin{tabular}{|l|c|c|c|c|c|c|c|c|c|}
\hline & \multicolumn{3}{|c|}{$\begin{array}{c}\text { 1 week } \\
(n=12)\end{array}$} & \multicolumn{3}{c|}{$\begin{array}{c}\text { 3 weeks } \\
(n=8)\end{array}$} & \multicolumn{3}{c|}{$\begin{array}{c}\text { 5 weeks } \\
(\text { n=4) }\end{array}$} \\
\hline & Preop & Postop & p value & Preop & Postop & p value & Preop & Postop & p value \\
\hline $\begin{array}{l}\text { Blue light } \\
\text { (Rod) }\end{array}$ & $\begin{array}{c}82.5 \\
( \pm 20.9)\end{array}$ & $\begin{array}{c}100.5 \\
( \pm 29.1)\end{array}$ & $\underline{0.030}$ & $\begin{array}{c}77.3 \\
( \pm 22.6)\end{array}$ & $\begin{array}{c}105.1 \\
( \pm 27.8)\end{array}$ & $\underline{0.039}$ & $\begin{array}{c}65.1 \\
( \pm 9.6)\end{array}$ & $\begin{array}{c}93.4 \\
( \pm 6.5)\end{array}$ & $\underline{0.031}$ \\
\hline $\begin{array}{l}\text { White light } \\
\text { (Rod-Cone) }\end{array}$ & $\begin{array}{c}145.7 \\
( \pm 27.2)\end{array}$ & $\begin{array}{c}157.6 \\
( \pm 51.4)\end{array}$ & 0.32 & $\begin{array}{c}137.8 \\
( \pm 21.6)\end{array}$ & $\begin{array}{c}184.3 \\
( \pm 33.4)\end{array}$ & $\underline{0.012}$ & $\begin{array}{c}129.5 \\
( \pm 17.6)\end{array}$ & $\begin{array}{c}151.25 \\
( \pm 14.7)\end{array}$ & 0.087 \\
\hline $\begin{array}{l}30 H z \text { flicker } \\
\text { (Cone) }\end{array}$ & $\begin{array}{c}14.5 \\
( \pm 4.2)\end{array}$ & $\begin{array}{c}16.4 \\
( \pm 6.6)\end{array}$ & 0.28 & $\begin{array}{c}13.2 \\
( \pm 4.2)\end{array}$ & $\begin{array}{c}16.3 \\
( \pm 5.6)\end{array}$ & 0.090 & $\begin{array}{c}12.1 \\
( \pm 3.9)\end{array}$ & $\begin{array}{c}15.4 \\
( \pm 3.2)\end{array}$ & $\underline{0.02}$ \\
\hline
\end{tabular}

Table 1: Full-field ERG. Averaged values \pm one standard deviation are given of b-wave amplitudes $(\mu \mathrm{V})$ for rod ERG (blue light), combined ERG (white light), and light-adapted single-flash cone ERG ( $30 \mathrm{~Hz}$ flicker). Four animals at each time-point were terminated after the ERG examination to provide material for histology and real-time PCR. The twotailed Student's paired t-test was used to compare pre- and post-operative values, and $\mathrm{p}<0.05$ was considered significant (underlined).

At all 3 time-points, amplitudes derived from the isolated rod response (blue light) is significantly increased to supernormal levels. Increased amplitudes are also seen for amplitudes derived from the combined rod-cone response (white light) at 3 weeks, and from the isolated cone response ( $30 \mathrm{~Hz}$ flicker) at 5 weeks. 


\begin{tabular}{|l|c|c|c|c|c|c|c|c|c|c|}
\hline & \multicolumn{3}{|c|}{$\begin{array}{c}\text { 1 week } \\
(n=12)\end{array}$} & \multicolumn{3}{c|}{$\begin{array}{c}\text { 3 weeks } \\
(n=8)\end{array}$} & \multicolumn{3}{c|}{$\begin{array}{c}\text { 5eeks } \\
(n=4)\end{array}$} \\
\hline & Preop & Postop & p value & Preop & Postop & p value & Preop & Postop & p value \\
\hline $\begin{array}{l}\text { mfERG } \\
\text { amplitude }\end{array}$ & $\begin{array}{c}8.7 \\
( \pm 2.5)\end{array}$ & $\begin{array}{c}8.2 \\
( \pm 2.6)\end{array}$ & 0.67 & $\begin{array}{c}8.0 \\
( \pm 2.1)\end{array}$ & $\begin{array}{c}9.2 \\
( \pm 2.7)\end{array}$ & 0.30 & $\begin{array}{c}8.0 \\
( \pm 1.2)\end{array}$ & $\begin{array}{c}6.1 \\
( \pm 1.5)\end{array}$ & 0.18 \\
\hline mfERG & $\begin{array}{c}27.1 \\
\text { latency }\end{array}$ & $\begin{array}{c}30.7 \\
( \pm 3.1)\end{array}$ & $\underline{0.0064}$ & $\begin{array}{c}27.6 \\
( \pm 2.1)\end{array}$ & $\begin{array}{c}30.1 \\
( \pm 1.7)\end{array}$ & $\underline{0.013}$ & $\begin{array}{c}27.5 \\
( \pm 2.4)\end{array}$ & $\begin{array}{c}30.6 \\
( \pm 2.2)\end{array}$ & $\underline{0.0021}$ \\
\hline
\end{tabular}

Table 2: Multifocal ERG (mfERG). Values are derived from traces in the 5 lowest rows of hexagons including the central part of the cone-rich visual streak. Averaged values \pm one standard deviation are given of amplitude $(\mu \mathrm{V})$ and latency $(\mathrm{mSec})$. Four animals at each time-point were terminated after the ERG examination to provide material for histology and real-time PCR. The two-tailed Student's paired t-test was used to compare pre- and post-operative values, and $\mathrm{p}<0.05$ was considered significant (underlined). The mfERG latency is significantly increased at 1, 3, and 5 weeks after laser treatment, while mfERG amplitudes is not significantly changed.

\section{Morphology}

All retinas remained attached on ophthalmoscopic examination and at dissection. One week after treatment, the induced laser spots appeared white, and after 3 weeks they were pigmented. Hematoxylin and eosin labeled sections revealed spots of focal destruction of the outer nuclear layer (ONL) with intraretinal migration of retinal pigment epithelial (RPE) cells. The retina between laser spots and outside the treated area appeared intact.

\section{Immunohistochemistry}

In untreated control eyes, cells corresponding to rod bipolar cells were seen throughout the retina in sections labeled with the PKC alpha antibody (Fig. 3a). Labeling within the outer segments (OS) was also seen. One and 3 weeks after laser photocoagulation, the PKC labeling in treated eyes displayed a lower intensity with fewer labeled rod bipolar cells compared with the untreated control eye (Fig. 3b-e). These findings were most obvious within the treated area. In areas outside laser spots, the PKC alpha labeling intensity was strongest in rod bipolar axonal terminals and weakest in the perikarya (Fig. 3b and e). Five weeks after treatment, no labeled rod bipolar cells were seen in 
any part of the retina (Fig. 3f-g). As in the normal retina, labeling of some OS were detected in all specimens throughout the retina.

In untreated control eyes, the GFAP antibody labeled well distinguished astrocytes in the optic nerve head area but no Müller cells. In laser treated eyes, the Müller cells displayed intense labeling for GFAP in the entire retina after 1 week (figure $4 a$ and $b$ ). Labeling intensity was highest in Müller cell end-feet and declined towards the outer limiting membrane. At 3 weeks, labeling was still pronounced in the laser treated area (fig 4c), but had declined in the periphery (fig 4d). Five weeks after treatment, GFAP labeling was confined to the laser spots (Fig. 4e and f).

\section{PKC Real-time PCR}

Real-time PCR revealed distinctly lower PKC alpha mRNA levels in laser treated eyes compared with untreated controls 1 week postoperatively (Fig. 5). At 3 weeks, PKC alpha mRNA levels were still lower in treated compared with untreated eyes, but the difference was less obvious. Similar patterns of PKC alpha mRNA levels were obtained when using beta-actin or GAPDH as reference gene (data not shown), indicating that these genes were trustworthy as references. 


\section{DISCUSSION}

In the present study, we have demonstrated that focal laser treatment in the rabbit eye influences the local and general retinal function as well as the expression of important retinal proteins. The experiment reproduces our previous results of GFAP up-regulation and PKC alpha down-regulation in the entire retina following treatment [9], but adds interesting electrophysiological findings which may expand our understanding of biochemical events involved in retinal signal processing.

Laser photocoagulation causes direct tissue damage to the retinal pigment epithelium (RPE) and photoreceptors with subsequent wound healing involving the inner retina as well [24]. Accordingly, when we measured the local retinal function in the laser treated area, we found a pathological response in the mfERG in the form of an increased latency at all 3 time points after surgery. Clinically, increased mfERG latency has been reported to be a sensitive indicator of macular disease [8,39]. The rabbit retina, however, does not include a macula, but instead a horizontally oriented visual streak where the cone concentration peaks at a mere 18000 cells $/ \mathrm{mm}^{2}$ [7]. Due to this comparatively low concentration of cones, a relatively severe lesion is required to obtain significant changes in the mfERG amplitudes [10]. We interpret the prolonged increased latency in mfERG recordings as an indicator of cone system related pathology related to cone photoreceptor damage induced by the laser treatment and conclude that this local effect, at least in the short term, is not reversible.

Perhaps more interestingly, we found that the effect of the focal laser photocoagulation on retinal function was not restricted to the treated area. This was evident from the profound change in GFAP and PKC alpha expression in the entire retina, but also by supernormal full-field ERG b-wave amplitudes after treatment. To understand the possible relationship between retinal function and morphological events, we in figure 6 we have compiled temporal data concerning changes in ERG and GFAP/PKC alfa expression. ERG supernormality has not previously been described after laser pho- 
tocoagulation, but the abnormal response has been found in a relatively unusual form of cone dystrophy, and also early in uveitis $[18,25,36]$. In the experimental situation, a disturbed phototransduction in the form of elevated levels of cyclic GMP by direct injection into outer segments or inhibition of phosphodiesterase (PDE) has been reported to amplify rod b-wave amplitudes substantially [26,31]. In addition, an unspecified delay in activity derived from inner nuclear cells has been implicated in the clinical form of cone dystrophy [16]. Interestingly, the PKC alpha isoenzyme is located both in the outer segments region as well as in rod bipolar cells in the inner nuclear layer and has been found to be a key player in the regulation of phototransduction as well as inner retinal signal transmission. In the outer segment, PKC alpha regulates phototransduction by phosphorylation of rhodopsin, transducin, PDE and arrestin [43]. In the inner retina, PKC alpha regulates signal transmission by modulating the activity of glutamate and gamma-aminobutyric acid (GABA) receptors [1.20]. GABA, which is considered a major inhibitory neurotransmitter, is found mainly in the amacrine cells, the synaptic targets of rod bipolar cells [6]. Inhibition of GABA neurotransmission enhances the ERG b-wave substantially [12]. In the present study, we have shown that PKC alpha expression in rod bipolar cells is progressively reduced by laser photocoagulation, while the expression in outer segments appears less affected. Given the important role of PKC alpha in inner retinal signal transmission, we suggest that the supernormal b-wave amplitudes seen in the full-field ERG after treatment may, at least in part, be cased by a reduced PKC alpha associated inhibitory regulation in rod bipolar cells.

Activation of PKC alpha in the rod bipolar cell induces its translocation from the cytosolic compartment in the entire cell to the membrane compartment of axon terminals in the inner part of the IPL where it is thought to play its functional role [28]. PKC alpha translocation is elicited by normal physiologic events such as rod bipolar cell depolarization [40]. Pharmacological intervention with phorbol esters and kainate as well as retinal ishemia can lead to excessive PKC alpha activation, 
characterized by translocation followed by depletion by unknown mechanisms [28-30]. In the present, as well as in our previous experiment, we noted PKC alpha translocation in rod bipolar cells followed by a progressive reduction in its expression over a 5 week period. The low level of PKC alpha mRNA found in real-time PCR specimens 1 week after treatment, indicates that laser photocoagulation in the early postoperative phase negatively influences PKC alpha synthesis. One relatively early effect of laser induced trauma is glutamate leakage from damaged neurons [33]. In the brain, glutamate excitotoxicity has been reported to impair protein synthesis [41]. A similar mechanism may also explain a diminished PKC alpha transcription in the retina following laser treatment. In 3-week specimens, the level of PKC alpha mRNA was higher than in 1-week counterparts while PKC alpha expression in immuolabeled sections progressively decreased from 1-5 weeks. This suggests that additional biochemical events not involving protein synthesis are involved in the depletion of the PKC alpha enzyme in rod bipolar cells. A clue to finding the mechanism behind this phenomenon may be obtained by examining the spatial and temporal distribution of the altered PKC alpha expression in relation to GFAP up-regulation found in Müller cells. An early sign of almost all retinal trauma is the well-characterized, but poorly understood, up-regulation of the Müller cell associated intermediate filament GFAP [23]. Humphrey and colleagues found that GFAP in Müller cells was up-regulated as early as 24 hours after application of single laser lesions in the rabbit eye with a spread of up-regulation far beyond the site of focal RPE and photoreceptor damage at 2-3 weeks [17]. To date, the cellular events leading to such spread are not fully understood, but several diffusible factors have been implicated in the process [23]. In the present study, we found a massive up-regulation of GFAP in the entire retina 1 week after treatment followed by a declining expression which, after 5 weeks was present only in laser treated spots. The rod bipolar "response", in the form of a down-regulated expression of PKC alpha, progressed over the 5-week period radiating from the treated area to the entire retina. The change in expression of both GFAP 
and PKC alpha thus appears to be initiated at the site of the lesion with successive spreading to the remaining retina. Another interesting comparison is the intracellular distribution of protein expression following laser treatment. Regardless of the stimulating event, GFAP up-regulation in Müller cells appears to be initiated in the end-feet region in the inner part of the retina, which possibly is the site of protein synthesis [23]. In the present study, we found that GFAP expression was more pronounced in the end-feet region 1 week after treatment and that $\mathrm{PKC}$ alpha was translocated to the neighboring innermost region of the inner plexiform layer. The relationship between GFAP and PKC alpha in the retina has not been extensively studied, but in other model systems, PKC alpha has been found to regulate both glial cell proliferation and phosphorylation of GFAP [2,27]. GFAP up-regulation after laser treatment may be cased by several factors. Our data does not support a direct causal link between GFAP and PKC alpha, but based on spatial and temporal changes of their expression it is interesting to speculate that Müller cell activation in the form of GFAP upregulation may be dependent on PKC alpha derived from rod bipolar cells.

To conclude, we in this paper have shown that focal laser photocoagulation induces biochemical and electrophysiological alterations reaching far beyond the treated area. PKC alpha activation followed by depletion appears to be the key event behind supernormal b-wave ERG amplitudes and GFAP up-regulation. The results may help us understand unexpected complications from focal laser photocoagulation as well as use the effects of the treatment ideally. 


\section{ACKNOWLEDGMENTS}

The authors would like to extend their gratitude towards Boel Nilsson and Karin Arnér for their skilled technical assistance. 


\section{REFERENCES}

1. Bettler B, Mulle C (1995). Review: neurotransmitter receptors. II. AMPA and kainate receptors. Neuropharmacology 34:123-39.

2. Brodie C, Kuperstein I, Acs P, Blumberg PM (1998). Differential role of specific PKC isoforms in the proliferation of glial cells and the expression of the astrocytic markers GFAP and glutamine synthetase. Brain Res Mol Brain Res 56:108-17.

3. Chuang HC, Kawano S, Arai M, Tsukada T, Kita M, Negi A, Honda Y (1992). The influence of argon laser panretinal photocoagulation on the rabbit ERG c-wave.. Acta Ophthalmol 70:303-7.

4. Ciavarella P, Moretti G, Falsini B, Porciatti V (1997). The pattern electroretinogram (PERG) after laser treatment of the peripheral or central retina. Curr Eye Res 16:111-5.

5. Early Treatment Diabetic Retinopathy Study Research Group (1985). Photocoagulation for diabetic macular edema. Early Treatment Diabetic Retinopathy Study report number 1. Arch Ophthalmol 103:1796-806.

6. Ehinger B, Falck B (1971). Autoradiography of some suspected neurotransmitter substances: GABA glycine, glutamic acid, histamine, dopamine, and L-dopa. Brain Res $33: 157-72$.

7. Famiglietti EV, Sharpe SJ. (1995). Regional topography of rod and immunocytochemically characterized "blue" and "green" cone photoreceptors in rabbit retina. Vis Neurosci 12:1151-75.

8. Gerth C, Hauser D, Delahunt PB, Morse LS, Werner JS (2003). Assessment of multifocal electroretinogram abnormalities and their relation to morphologic characteristics in patients with large drusen. Arch Ophthalmol 121:1404-14.

9. Ghosh F, Gjörloff K (2005). Protein kinase C expression in the rabbit retina after laser photocoagulation. Graefe's Arch Clin Exp Ophtahalmol 243:803-810.

10. Gjörloff K, Andréasson S, Ghosh F (2006). mfERG in normal and lesioned rabbit retina. Graefe's Arch Clin Exp Ophtahalmol 244:83-9.

11. Gjörloff KW, Andréasson S, Ehinger B (2004). Standardized full-field and multifocal electroretinography in rabbits. Doc Opthalmol 109:163-168.

12. Gottlob I, Wundsch L, Tuppy FK (1988). The rabbit electroretinogram: effect of GABA and its antagonists.. Vision Res 28:203-10.

13. Greenstein VC, Chen H, Hood DC, Holopigian K, Seiple W, Carr RE (2000). Retinal function in diabetic macular edema after focal laser photocoagulation. Invest Ophthalmol Vis Sci 41:3655-64.

14. Hammer RM, Yinon U, Rosner M, Solomon A (1996-1997). Time course of electroretinographic recovery following argon laser photocoagulation in cats. Metab Pediatr Syst Ophthalmol 19-20:1-5. 
15. Henricsson M, Heijl A (1994). The effect of panretinal laser photocoagulation on visual acuity, visual fields and on subjective visual impairment in preproliferative and early proliferative diabetic retinopathy. Acta Ophthalmol. 72:570-5.

16. Hood DC, Cideciyan AV, Halevy DA, Jacobson SG (1996). Sites of disease action in a retinal dystrophy with supernormal and delayed rod electroretinogram b-waves. Vision Res 36:889-901.

17. Humphrey MF, Constable IJ, Chu Y, Wiffen S (1993). A quantitative study of the lateral spread of Muller cell responses to retinal lesions in the rabbit. J Comp Neurol 334:545-558.

18. Ikeda H, Franchi A, Turner G, Shilling J, Graham E (1989). Electroretinography and electrooculography to localize abnormalities in early-stage inflammatory eye disease. Doc Ophthalmol 73:387-94.

19. Johansson K, Malmsjö M, Ghosh F (2006). Tailored Vitrectomy and Laser Photocoagulation Without Scleral Buckling for Primary Rhegmatogenous Retinal Detachment. Br J Ophtalmol 90:1286-91.

20. Jung CS, Lee SJ, Paik SS, Bai SH. (2000). Run-up of gamma-aminobutyric acid(C) responses in catfish retinal cone-horizontal cell axon-terminals is modulated by protein kinase A and C. Neurosci Lett. 282:53-6.

21. Khosla PK, Rao V, Tewari HK, Kumar A (1994). Contrast sensitivity in diabetic retinopathy after panretinal photocoagulation. Ophthalmic Surg 25:516-20.

22. Leibu R, Davila E, Zemel E, Bitterman N, Miller B, Perlman I (1999). Development of laser-induced retinal damage in the rabbit.. Graefe's Arch Clin Exp Ophtahalmol 237:991-1000.

23. Lewis GP, Fisher SK (2003). Up-regulation of glial fibrillary acidic protein in response to retinal injury: its potential role in glial remodeling and a comparison to vimentin expression. Int Rev Cytol 230:263-90.

24. Marshall J (1989). Structural aspects of laser-induced damage and their functional implications. Health Phys 56:617-24.

25. Michaelides M, Holder GE, Webster AR, Hunt DM, Bird AC, Fitzke FW, Mollon JD, Moore AT (2005). A detailed phenotypic study of "cone dystrophy with supernormal rod ERG". Br J Ophtalmol 89:332-9.

26. Nicol GD, Miller WH (1978). Cyclic GMP injected into retinal rod outer segments increases latency and amplitude of response to illumination. Proc Natl Acad Sci U S A 75:5217-20.

27. Noetzel MJ (1990). Phosphorylation of the glial fibrillary acidic protein. J Neurosci Res 27:184-92.

28. Osborne NN, Barnett NL (1992). An intraocular injection of kainate induces expression of c-fos-like protein and activation of protein kinase $\mathrm{C}$ (alpha) in specific rabbit retinal neurones. Brain Res Mol Brain Res 15:108-12. 
29. Osborne NN, Broyden NJ, Barnett NL, Morris NJ (1991). Protein kinase C (alpha and beta) immunoreactivity in rabbit and rat retina: effect of phorbol esters and transmitter agonists on immunoreactivity and the translocation of the enzyme from cytosolic to membrane compartments. Neurochem 57:594-604.

30. Osborne NN, Wood J, Muller A (1995). The influence of experimental ischaemia on protein kinase $\mathrm{C}$ and the GABAergic system in the rabbit retina. Neuropharmacology 34:1279-88.

31. Pawlyk BS, Sandberg MA, Berson EL (1991). Effects of IBMX on the rod ERG of the isolated perfused cat eye: antagonism with light, calcium or L-cis-diltiazem. Vision Res 31:1093-7.

32. Pender PM, Benson WE, Compton H, Cox GB (1981). The effects of panretinal photocoagulation on dark adaptation in diabetics with proliferative retinopathy. Ophthalmology 88:635-8.

33. Rosner M, Solberg Y, Turetz J, Belkin M (1997). Neuroprotective therapy for argon-laser induced retinal injury. Exp Eye Res 65:485-95.

34. Saran BR, Brucker AJ (1995). Macular epiretinal membrane formation and treated retinal breaks.. Am J Ophthalmol 120:480-5.

35. Schechner R, Gdal-on M, Cohen D, Meyer E, Zonis S, Perlman I (1987). Recovery of the electroretinogram in rabbits after argon laser photocoagulation. Invest Ophthalmol Vis Sci 28:1605-13.

36. Stanford MR, Robbins J, Kasp E, Dumonde DC (1992). Passive administration of antibody against retinal S-antigen induces electroretinographic supernormality. Invest Ophthalmol Vis Sci 33:30-5.

37. The Branch Vein Occlusion Study Group. (1984). Argon laser photocoagulation for macular edema in branch vein occlusion. Am J Ophthalmol 98:271-82.

38. The Macular Photocoagulation Study Group (1990). Krypton laser photocoagulation for neovascular lesions of age-related macular degeneration. Results of a randomized clinical trial. Arch Ophthalmol 108:816-24.

39. Tyrberg M, Ponjavic V, Lovestam-Adrian M (2005). Multifocal electroretinography (mfERG) in insulin dependent diabetics with and without clinically apparent retinopathy. Doc Ophthalmol 110:137-43.

40. Vaquero CF, Velasco A, de la Villa P (1996). Protein kinase C localization in the synaptic terminal of rod bipolar cells. Neuroreport 7:176-80.

41. Virgili M, Contestabile A, Barnabei O (1995). Simultaneous blockade of non-NMDA ionotropic receptors and NMDA receptor-associated ionophore partially protects hippocampal slices from protein synthesis impairment due to simulated ischemia. Hippocampus 5:91-7.

42. Wolbarsht ML, Landers MB 3rd. (1980). The rationale of photocoagulation therapy for proliferative diabetic retinopathy: a review and a model. Ophthalmic Surg 11:235-45. 
43. Wood JPM, McCord RJ, Osborne NN (1997). Retinal protein kinase C. Neurochem Int 30:119-136. 


\section{FIGURE LEGENDS}

Figure 1. Illustration of the area of laser treatment, extending from the central myelinated streak inferiorly through the cone-rich visual streak

Figure 2. Demonstration of typical full-field ERG curves before and after laser treatment in the rabbit eye. ERG traces derived from b-wave amplitudes are enhanced postoperatively.

Figure 3. PKC labeling. Cryostat sections. Scale bars $=50.1 \mu \mathrm{m}$.

In the normal rabbit retina (a), labeling is present in the rod bipolar cells, extending from the inner nuclear layer (INL) to the inner plexiform layer (IPL). Labeling is also present in the outer segment region (OS). At 1 and 3 weeks after laser treatment, the PKC labeling is reduced in the treated area (b and d), and to some extent also in the periphery (c and e). Labeling intensity of rod bipolar cell axon terminals in the IPL is stronger than in the perikarya in the INL (b and e). At 5 weeks no labeled rod bipolar cells is seen in the treated area (f), or in the periphery $(\mathbf{g})$, while labeled outer segments are noted in the untreated area.

Figure 4. GFAP labeling. Cryostat sections. Scale bar $=100 \mu \mathrm{m}$.

No labeling is seen in an untreated control eye (a). Intense labeling is seen at 1 week both in the treated area (b) and in the periphery (c). Labeling is strongest in the Müller cell end-feet (arrowheads) and declines towards the outer limiting membrane (OLM). After 3 and 5 weeks, the labeling is still intense in the treated area (d and $\mathbf{f})$, but has declined in the periphery (e and $\mathbf{g})$.

Figure 5. PKC alpha mRNA levels assessed by real-time PCR, in the rabbit retina $1(n=4)$ and 3 $(n=4)$ weeks after focal laser photocoagulation (grey) compared with unoperated eyes (white). Values are presented as arbitrary units \pm SEM relative to beta-actin levels. One week after surgery, the PKC alpha mRNA level is drastically decreased in the treated eye. After 3 weeks, the decrease is less pronounced.

Figure 6. Graphical representation (arbitrary scale) of the general response in the rabbit retina after focal laser photocoagulation. Rod and cone full-field ERG b-wave amplitudes increase to supernormal values postoperatively following an up-regulation of glial fibrillary acidic protein (GFAP) in Müller cells, and down-regulation of rod bipolar cell associated PKC-alpha. 


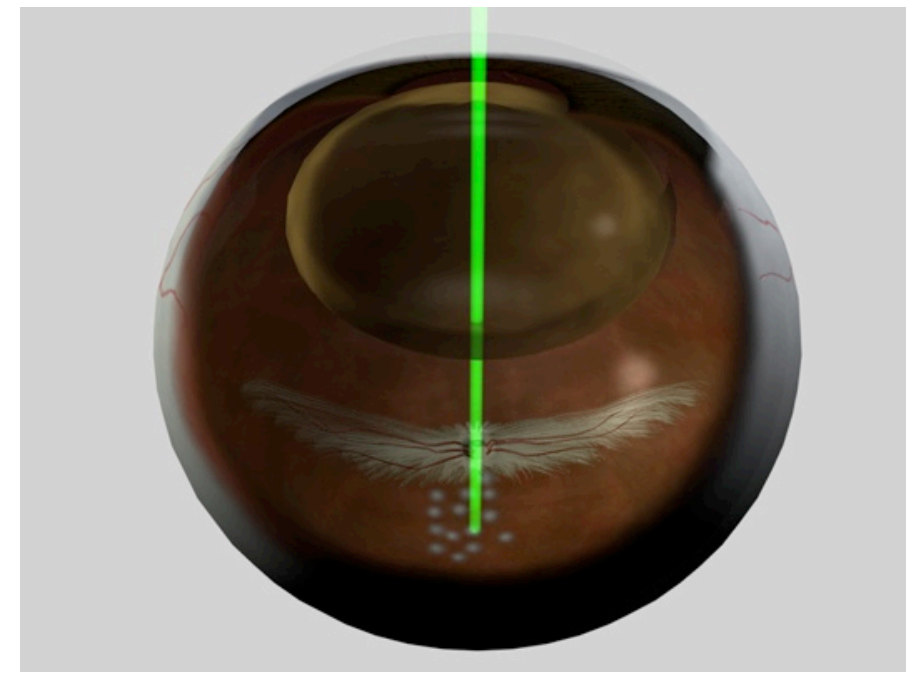

Figure 1 


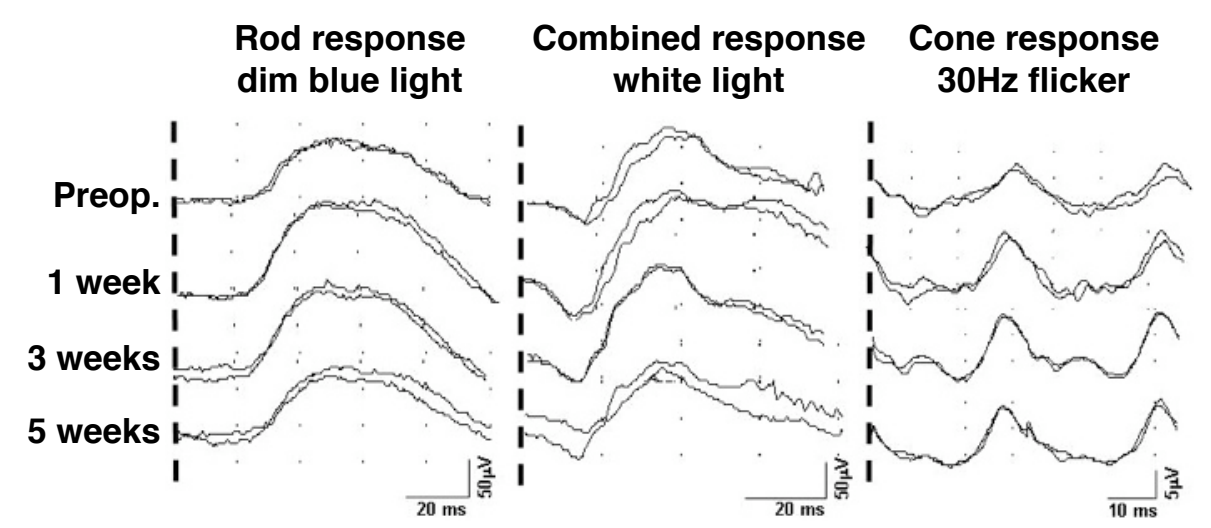

Figure 2 


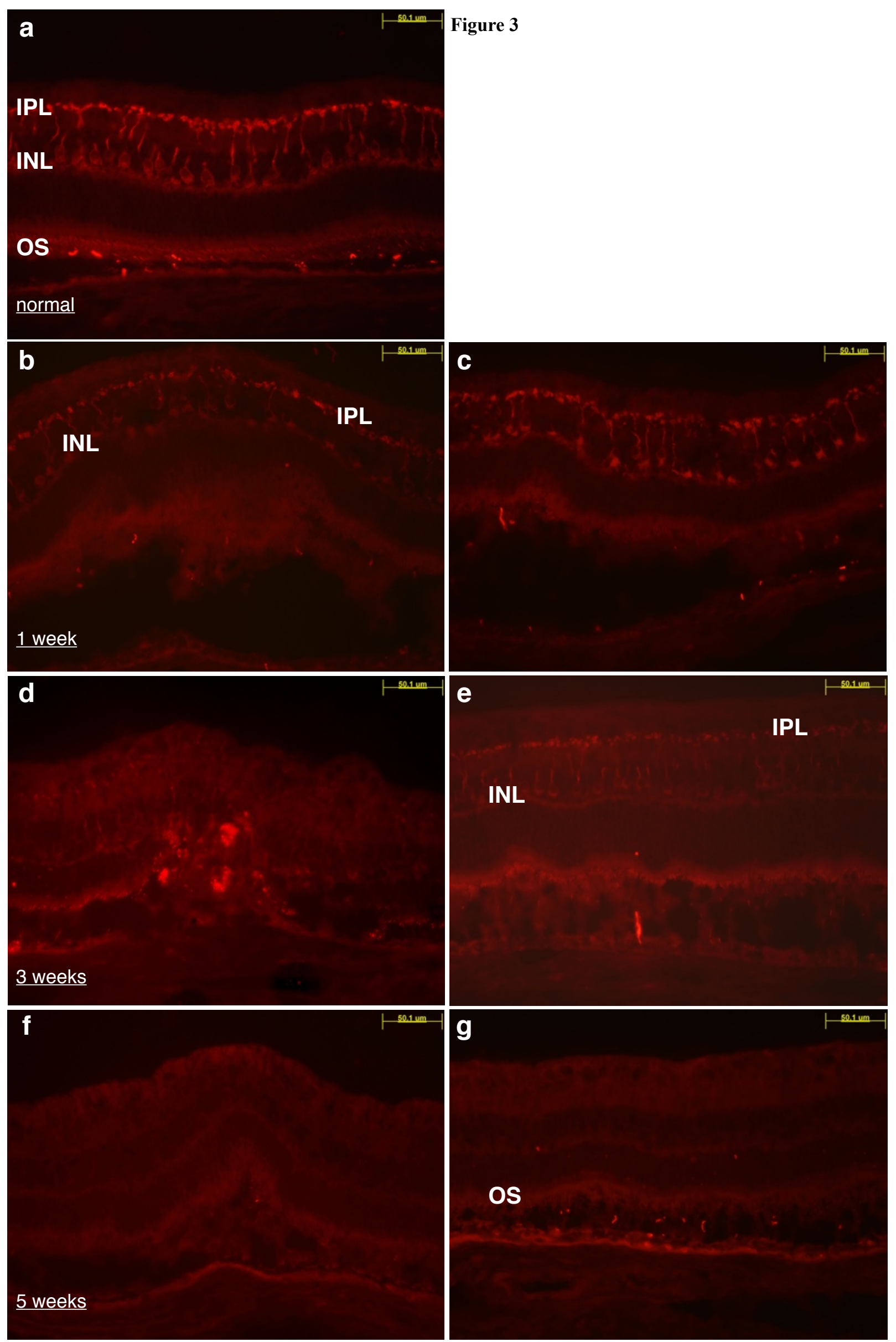




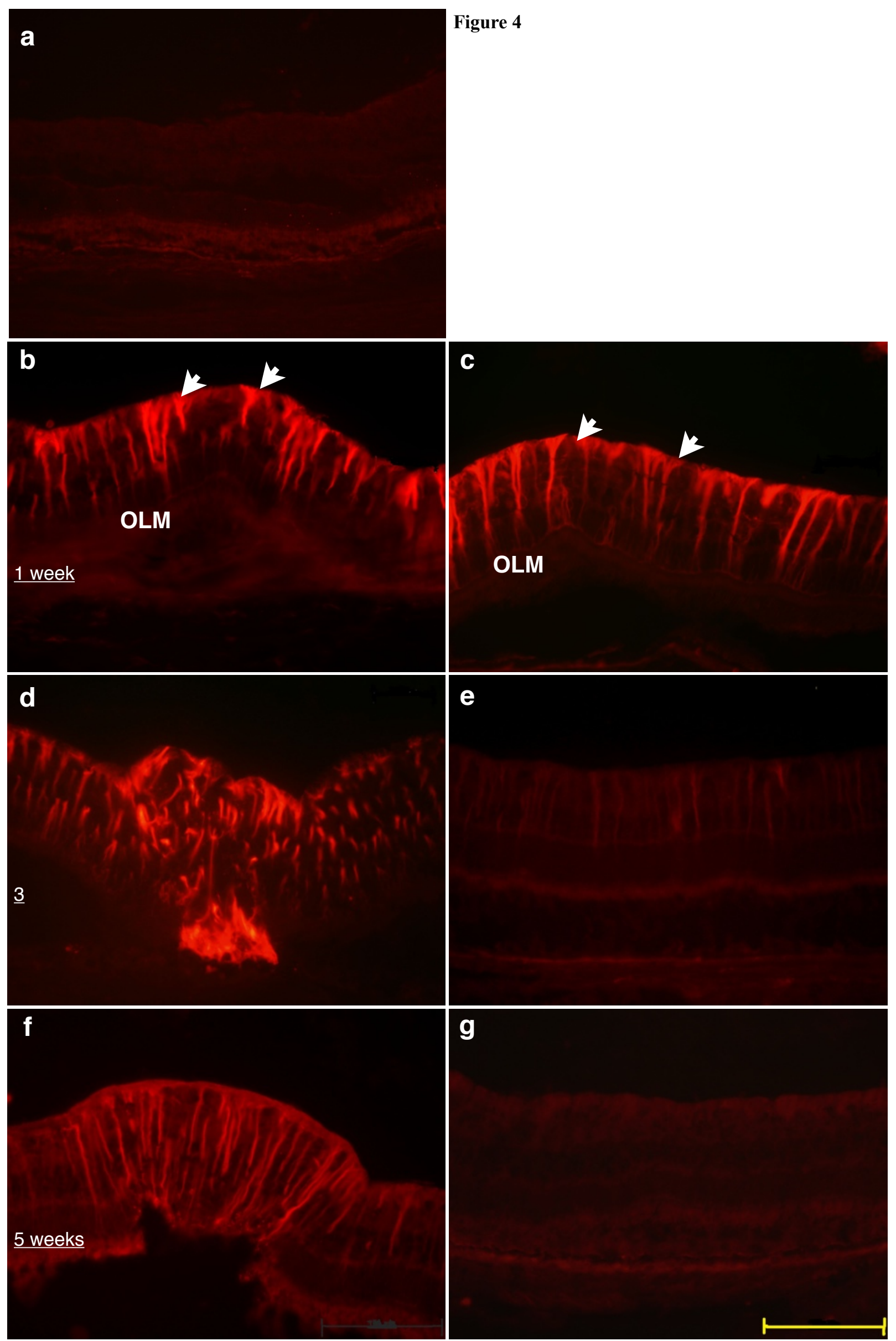




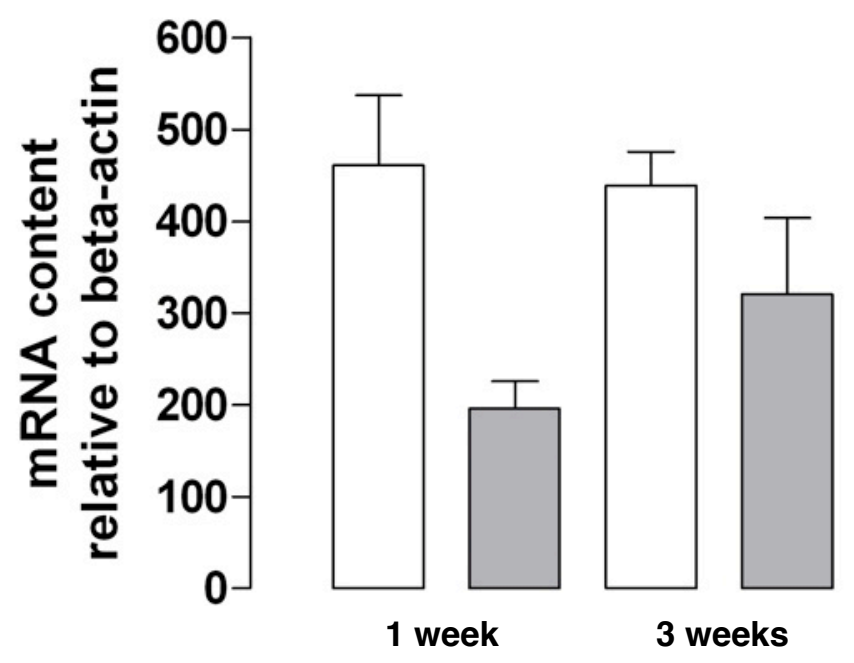

Figure 5 


\section{0}

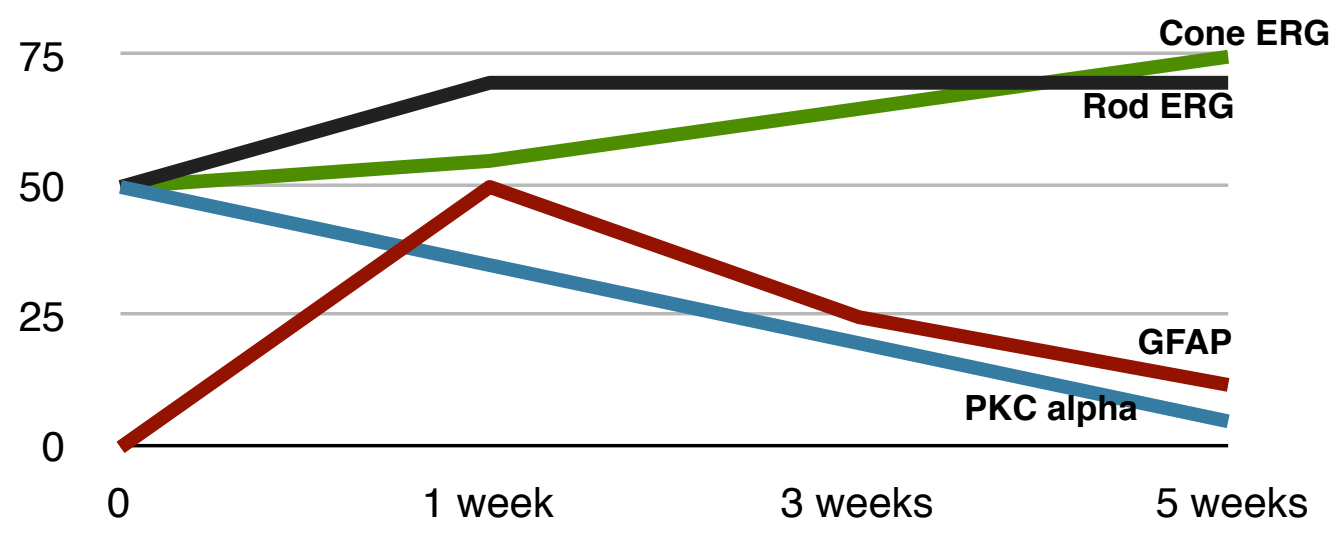

Figure 6 